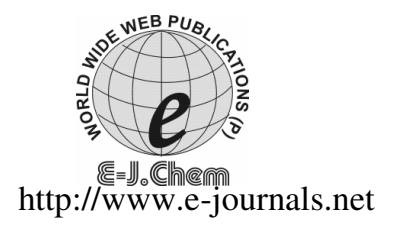

ISSN: 0973-4945; CODEN ECJHAO

E-Journal of Chemistry

2011, 8(3), 1186-1199

\title{
Ion Exchange Study of Some New Copolymer Resins Derived from 8-Hydroxyquinoline- 5-sulphonic Acid, Biuret and Formaldehyde
}

\author{
P.A. DHAKITE* and W.B. GURNULE \\ *Department of Applied Chemistry \\ Shri. Shankarprasad Agnihotri College of Engg \\ Ramnagar, Wardha - 442 001, India \\ Department of Chemistry, Kamla Nehru College \\ Sakkaradara, Nagpur - 440 009, India \\ pravinchemkb@rediffmail.com
}

Received 2 October 2010; Accepted 27 November 2010

\begin{abstract}
Copolymer resins (8-HQSABF) were synthesized by the condensation of 8-hydroxyquinoline-5-sulphonic acid and biuret with formaldehyde in the presence of hydrochloric acid as catalyst, proved to be selective chelation ion exchange copolymer resins for certain metals. Chelation ion exchange properties to these polymers were studied for $\mathrm{Cu}^{2+}, \mathrm{Cd}^{2+}, \mathrm{Co}^{2+}$ and $\mathrm{Zn}^{2+}$ ions. A batch equilibrium method was employed in the study of the selectivity of the distribution of a given metal ions between the polymer sample and a solution containing the metal ion. The study was carried out over a wide $\mathrm{pH}$ range and in a media of various ions strengths. The polymer showed a higher selectivity for $\mathrm{Cu}^{2+}$ ions than for $\mathrm{Cd}^{2+}, \mathrm{Co}^{2+}$ and $\mathrm{Zn}^{2+}$ ions. Hence on the basis of above studies these copolymer may be used as semiconductors, surface coating, ion-exchangers, materials for rechargeable battery cell in various electronic industries, plastic materials, elastomers and in boiler plants
\end{abstract}

Keywords: Synthesis, Ion-exchangers, Batch equilibrium, Distribution ratio, Resin

\section{Introduction}

Ion exchange may be defined as the reversible exchange of ions between the substrate and surrounding medium. Ion exchange technique can remove traces of ion impurities from water/process liquors and given out a product of ultra pure quality in a single efficient and techno-economically viable manner. Ion exchangers are widely used in analytical chemistry hydrometallurgy, antibiotics, purification and separation of radioisotopes and find large application in water treatment and pollution control ${ }^{1,2}$. Lutfor et al. ${ }^{3}$ prepared a chelating 
ion exchange resin containing amidoxime functional group. The chelating poly (amidoxime) resin was characterized by FTIR spectra, TG and DSC analyses. The chelating behavior of the prepared resin was studied with $\mathrm{Cu}(\mathrm{II}), \mathrm{Zn}(\mathrm{II}), \mathrm{Ni}(\mathrm{II}), \mathrm{Cd}(\mathrm{II})$ and $\mathrm{Pb}(\mathrm{II})$ metal ions. Samir et al synthesized ion exchange resin from 8-quinolinyl methacrylate and characterized by conventional methods. The thermal analysis was carried out using TGA and DSC. The metal ion uptake capacities of synthesized copolymers were estimated by batch equilibration method using different metal ion solutions under different experimental conditions.

Three phenol-formaldehyde chelating resins, poly(8-hydroxyquinoline-5,7 diylmeth ylene), poly(8-hydroxyquinoldine-5,7 diylmethylene) and poly (2-aminopheno 1-5,7 diylmeth ylene) were synthesized and characterized by Ebraheem ${ }^{5}$. The chelating characteristics of these polymers were studied by a batch equilibrium technique. The ion exchange capacity, effect of electrolyte on metal ion up take, rate of metal uptake and distribution of metal ion at different $\mathrm{pH}$ with resin copolymer derived from thiosemicarbazone derivatives of phenolic compound shows higher order than the resin copolymer derived from semicarbazone derivatives ${ }^{6}$. Recently much work has been carried out to study the ion exchange properties of anchoring functional chelating groups on the polymeric network. But as compared to anchored resins, the synthesized resins are more advantageous because the synthesized insoluble functionalized polymer can provide good stability and good flexibility in working conditions.

Rivas et $a .^{7}$ synthesized cross linked poly [3-(methacryloyl- amino)-propyl]-dimethyl (3-sulfopropyl)ammoniumhydroxide-co-2-acryl-amidoglycolic acid [PCMAAPDSA-coAGCO] by radical polymerization and tested the synthesized polymer as an absorbent under competitive and non-competitive conditions for $\mathrm{Cu}$ (II), $\mathrm{Cd}(\mathrm{II}), \mathrm{Hg}$ (II), $\mathrm{Zn}$ (II), $\mathrm{Pb}$ (II) and $\mathrm{Cr}(\mathrm{III})$ by batch and column equilibrium procedures. They reported that resin metal ion equilibrium was achieved before $1 \mathrm{~h}$. The resin showed a maximum retention capacity value of 1.084 m.equ. $\mathrm{g}^{-1}$ for $\mathrm{Hg}(\mathrm{II})$ at $\mathrm{pH} 2$. The recovery of the resin was investigated at $20{ }^{\circ} \mathrm{C}$ under different concentration of $\mathrm{HNO}^{3}$ and $\mathrm{HClO}_{4}$.

Jadhao et $_{\text {al. }}{ }^{8}$ synthesized a terpolymer resin by condensation of 2,2'dihydroxybiphenyl and formaldehyde in the presence of acid catalyst. They studied chelating ion exchange properties of this polymer for $\mathrm{Fe}(\mathrm{III}), \mathrm{Cu}(\mathrm{II}), \mathrm{Ni}$ (II), $\mathrm{Zn}$ (II), $\mathrm{Cd}$ (II) and $\mathrm{Pb}$ (II) ions. A batch equilibrium method was employed in the study of the selectivity of metal ion uptake involving the measurement of the distribution of a given metal ion between the polymer sample and a solution containing metal ions. The study was carried out over a $\mathrm{pH}$ range and in media of various ionic strengths. They reported that the polymer showed a higher selectivity for $\mathrm{Fe}(\mathrm{III}), \mathrm{Cu}(\mathrm{II})$ and $\mathrm{Ni}$ (II) than for $\mathrm{Co}(\mathrm{II}), \mathrm{Zn}$ (II) $\mathrm{Cd}$ (II) and $\mathrm{Pb}$ (II) ions.

So for no resin based on 8-hydroxyquinoline-5-sulphonic acid, biuret and formaldehyde in acidic media has been synthesized for the quantitative separation of transition metal ions. As industrial influence often rich in transition metal ions, removal of these metals use an important task for industries. Therefore we have studied the use of ion exchanger for removal and separation of heavy metal ions. In this paper, synthesis and characterization of the above resin are reported together with the condition for the effective separation of transition metal ions.

\section{Experimental}

The chemicals 8-hydroxyquinoline-5-sulphonic acid, biuret and formaldehyde (37\%) used are of AR grade and chemically pure which is purchased from Merck. Solvents like $N, N$-dimethyl formamide and dimethylsulphoxide were used after distillation. 


\section{Preparation of 8-HQSABF coploymers}

A mixture of 8-hydroxyquinoline-5-sulphonic acid (2.3424 g, 0.1 mole), biuret (1.030 g, 0.1 mole), formaldehyde $(7.5 \mathrm{~mL}, 0.2$ mole) in the presence of $200 \mathrm{~mL} 2 \mathrm{M}$ hydrochloric acid was refluxed in an oil bath at $130 \pm 2{ }^{\circ} \mathrm{C}$ for $5 \mathrm{~h}$ with stirring, The separated yellowish brown coloured resin was washed with cold water dried and powdered. The powder was repeatedly washed with hot water to remove unreacted monomer. The air dried copolymer was extracted with solvent ether to remove 8-hydroxyquinoline-5-sulphonic acidformaldehyde copolymer and traces of monomer which might be present along with the 8-HQSABF copolymer. It was purified by dissolving in $8 \% \mathrm{NaOH}$, filtered and reprecipitated by gradual drop wise addition of $1: 1(\mathrm{v} / \mathrm{v})$ conc. $\mathrm{HCl} / \mathrm{H}_{2} \mathrm{O}$ with constant and rapid stirring. The copolymer resin (8-HQSABF) (1:1:2) so obtained was filtered, washed with hot water dried in air, powdered and kept in vacuum over anhydrous $\mathrm{CaCl}_{2}$. Yield of resin was $65 \%$ resin does not melt up to $220{ }^{\circ} \mathrm{C}$. Different copolymer resin samples by varying the molar proportions (ratios) of reactant monomers were synthesized viz. 8-HQSABF (1:2:1), 8-HQSABF (2:1:3), 8-HQSABF (3:1:4), 8-HQSABF (4:2:1).

Table 1. Synthesis and physical data of 8-HQSABF copolymer resins

\begin{tabular}{|c|c|c|c|c|c|c|c|c|}
\hline \multirow[b]{2}{*}{ Copolymer } & \multicolumn{3}{|c|}{ Reactants } & \multirow[b]{2}{*}{$\begin{array}{l}\dot{j} \\
\dot{\Xi} \\
\underset{\Xi}{\Xi}\end{array}$} & \multirow[b]{2}{*}{ 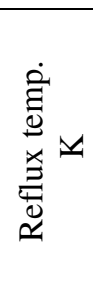 } & \multirow[b]{2}{*}{ 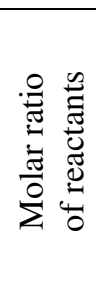 } & \multirow[b]{2}{*}{$\begin{array}{l}0 \\
i 0 \\
i=\end{array}$} & \multirow[b]{2}{*}{ 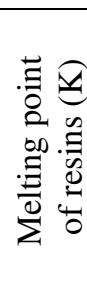 } \\
\hline & 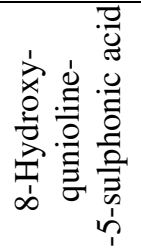 & 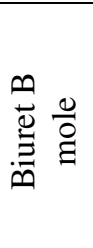 & 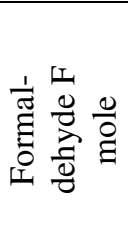 & & & & & \\
\hline 8-HQSABF-I & 0.1 & 0.1 & 0.2 & 200 & 403 & $1: 1: 2$ & 60.12 & 493 \\
\hline 8-HQSABF-II & 0.2 & 0.1 & 0.3 & 200 & 403 & $2: 1: 3$ & 62.05 & 621 \\
\hline 8-HQSABF-III & 0.3 & 0.1 & 0.4 & 200 & 403 & $3: 1: 4$ & 66.78 & 500 \\
\hline 8-HQSABF-IV & 0.4 & 0.1 & 0.5 & 200 & 403 & $4: 1: 5$ & 70.59 & 563 \\
\hline
\end{tabular}

\section{Analytical and physicochemical studies}

The intrinsic viscosities were determined using a Tuan-Fuoss viscometer ${ }^{9}$ at six different concentrations ranging from $0.3 \mathrm{wt} \%$ to $0.05 \mathrm{wt} \%$ of resin in $\mathrm{DMF}$ at $300{ }^{\circ} \mathrm{C}$. Intrinsic viscosity ( $\eta$ ) was calculated by the Huggin's ${ }^{9}$ eqn.(1) and Kraemer ${ }^{9}$ eqn.(2). The elemental analysis was carried out on a Perkin Elmer 2400 elemental analyzer instruments. The UV-Visible studies were carried out using Hitachi 330 UV-VIS-NIR spectrometer in the range $200-850 \mathrm{~nm}$. The Infrared spectrum was recorded in the region of $500-4000 \mathrm{~cm}^{-1}$ on Perkin Elmer spectrum RXI FT-IR spectrometer. ${ }^{1} \mathrm{H}$ NMR studied using Bruker Avance-II FT -NMR spectrometer in DMSO- $\mathrm{d}_{6}$ solvent. All the analytical and spectral studies for the newly synthesized copolymer were carried out at Sophisticated Analytical Instrumentation Facility (SAIF) Punjab University, Chandigarh.

\section{Ion exchange properties}

To decide the selectivity of $8-\mathrm{HQSABF}$ copolymers, we studied the influence of various electrolytes, the rate of metal uptake and distribution of metal ions between the copolymer and solution. The results of the batch equilibrium study carried out with the copolymer samples are presented and discussed. 
Determination of metal uptake in the presence of electrolytes of different concentrations The copolymer sample (25 mg) was suspended in an electrolyte solution of $\mathrm{NaNO}_{3}(25 \mathrm{~mL})$ of known concentration. The $\mathrm{pH}$ of the suspension was adjusted to the required value by using either $0.1 \mathrm{~N} \mathrm{HCl}$ or $0.1 \mathrm{~N} \mathrm{NaOH}$. The suspension was stirred for a period of $24 \mathrm{~h}$ at $25{ }^{\circ} \mathrm{C}$. To this suspension $2 \mathrm{~mL}$ of $0.1 \mathrm{M}$ solution of the metal ion was added and the $\mathrm{pH}$ was adjusted to the required value. The mixture was again stirred at $25{ }^{\circ} \mathrm{C}$ for $24 \mathrm{~h}$ and filtered. The solid was washed and the filtrate and washings were combined and the metal ion content was determined by titration against standard EDTA. The amount of metal ion uptake of the polymer was calculated from the difference between a blank experiment without polymer and the reading in the actual experiments. The experiment was repeated in the presence of other two electrolytes such as $\mathrm{NaCl}$ and $\mathrm{NaClO}_{4}$.

Evaluation of the rate of metal uptake

In order to estimate the time required to reach the state of equilibrium under the given experimental conditions, a series of experiments of the type describe above were carried out, in which the metal ion taken up by the chelating resins was determined from time to time at $25{ }^{\circ} \mathrm{C}$ (in the presence of $25 \mathrm{~mL}$ of $1 \mathrm{M} \mathrm{NaNO}_{3}$ solution). It was assumed that under the given conditions, the state of equilibrium was established within $24 \mathrm{~h}$. The rate of metal ions uptake is expressed as percentage of the amount of metal ions taken up after a certain time related to the time, which required for the state of equilibrium.

\section{Evaluation of the distribution of the metal ions at different $\mathrm{pH}$}

The distribution of each metal ions between the polymer phase and the aqueous phase was determined at $25^{\circ} \mathrm{C}$ and in the presence of $1 \mathrm{M} \mathrm{NaNO}_{3}$ solution. The experiments were carried out as described above at different $\mathrm{pH}$ values. The distribution ratio ' $\mathrm{D}$ ' is defined by following eqn.

$$
\mathrm{D}=\frac{\text { Wt. }(\mathrm{mg}) \text { of metal ions taken up by } 1 \mathrm{~g} \text { of copolymers }}{\text { Wt. }(\mathrm{mg}) \text { of metal ion present in } 1 \mathrm{~mL} \text { of copolymers }}
$$

\section{Results and Discussion}

The copolymers which have been used in the present investigation were prepared by the reaction Scheme 1. The resin sample was pale yellow in color, insoluble in commonly used solvent, but was soluble in $N N$-dimethyl formamide, aqueous sodium and potassium hydroxide. No precipitation and degradation occurs of resin in all the solvents. These resins were analyzed for carbon, hydrogen and nitrogen content (Table 2).
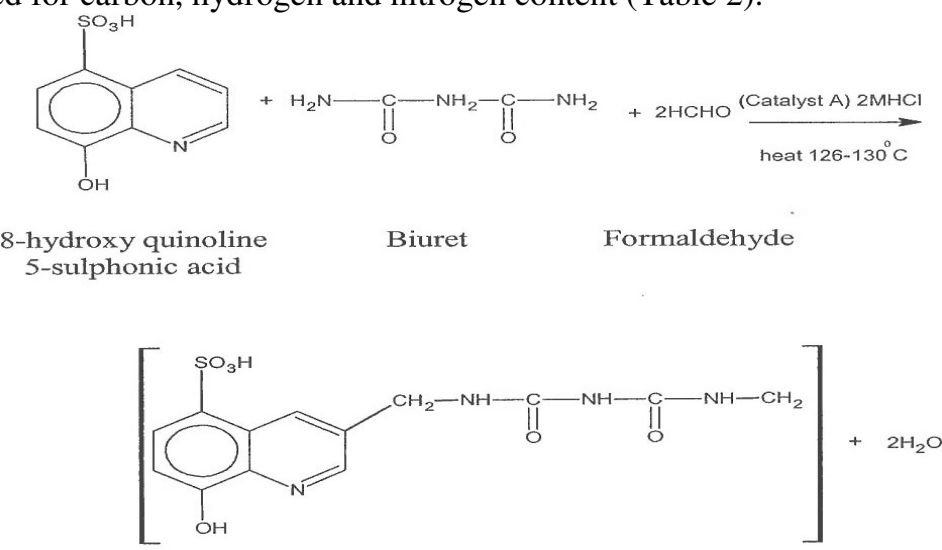

Scheme 1 


\section{Viscometric study}

Viscometric measurements were carried out in $\mathrm{N} \mathrm{N}$-dimethyl formamide solution at $30{ }^{\circ} \mathrm{C}$ using a Tuan Fouss $^{9}$ viscometer. Reduced viscosity versus concentration (3-0.5\%) was plotted for each set of data. The intrinsic viscosity [ $\eta$ ] was determined by the corresponding linear plots (Figure 1). The following equations were used to determine Huggin's ${ }^{9}$ and Krammer's ${ }^{9}$ constant, respectively:
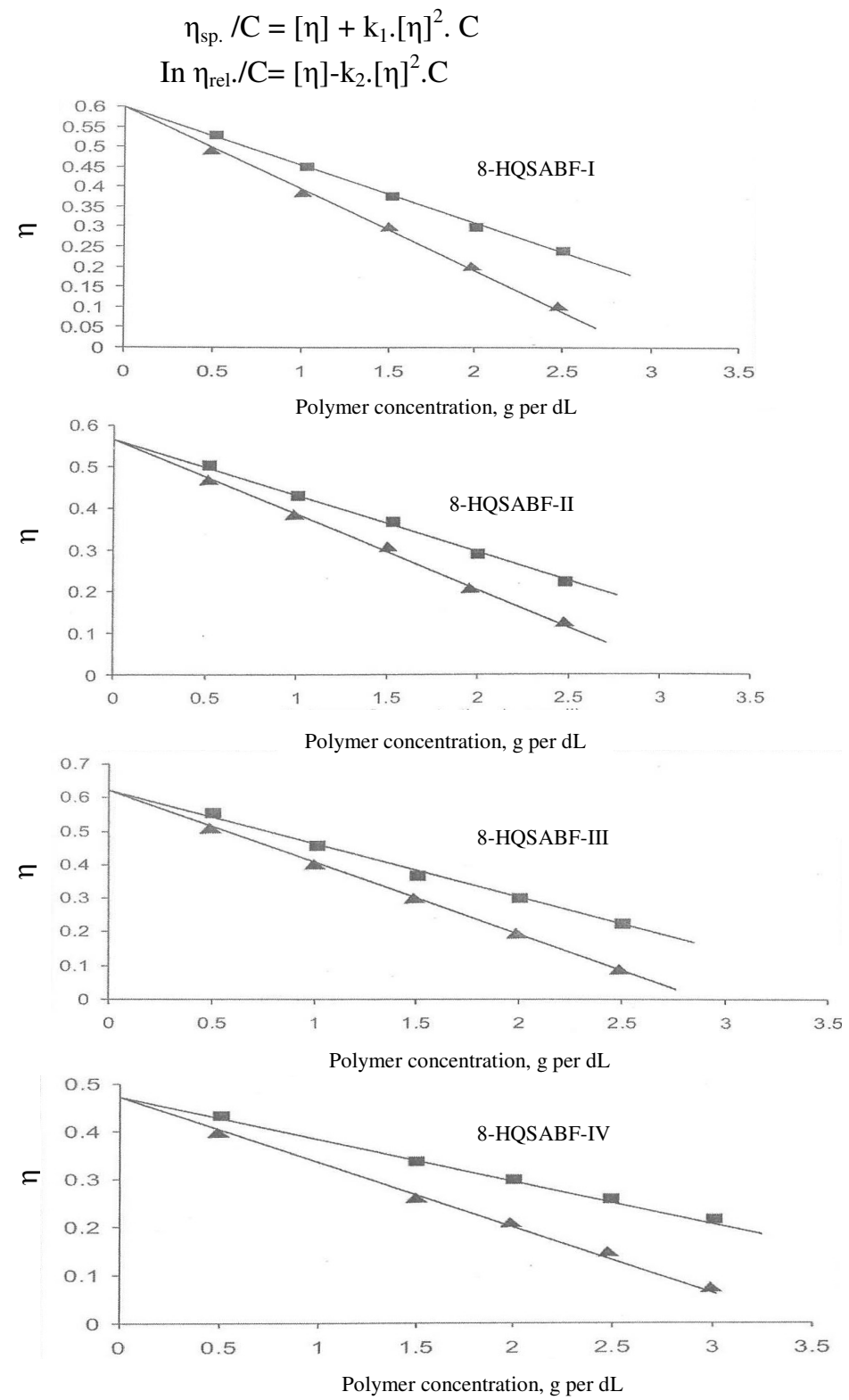

Figure 1. Viscometric plots of copolymers, 8-HQSABF-I, 8-HQSABF-II, 8-HQSABF- III, 8-HQSABF - IV 
According to above relations, a plot of $\eta_{\text {sp }} / \mathrm{C}$ and $\eta_{\text {rel }} / \mathrm{C}$ against $\mathrm{C}$ were linear with slopes of $k_{1}$ and $k_{2}$ respectively. Intercepts on the viscosity function axis gave $[\eta]$ valid in both plots The calculated values of the constants $\mathrm{k}_{1}$ and $\mathrm{k}_{2}$ for the intrinsic viscosities (Table 2) satisfy the relation $\mathrm{k}_{1}+\mathrm{k}_{2}=0.5$ favourably ${ }^{10}$.It was observed that copolymers having higher Mn show a higher value of $[\eta]$.

Table 2. Elemental analysis data of 8-HQSABF copolymers resins

\begin{tabular}{cccccccc}
\hline \multirow{2}{*}{ Copolymers } & \multicolumn{2}{c}{$\mathrm{C}, \%$} & \multicolumn{2}{c}{$\mathrm{H}, \%$} & \multicolumn{2}{c}{$\mathrm{N}, \%$} & $\begin{array}{c}\text { Intrinsic } \\
\text { Viscosity [ } \mathrm{\eta}]\end{array}$ \\
\cline { 2 - 8 } & Calc. & Found & Calc. & Found & Calc. & Found & \\
\hline 8-HQSABF - I & 48.54 & 48.14 & 4.03 & 4.04 & 16.31 & 15.31 & 0.55 \\
8-HQSABF - II & 46.54 & 46.39 & 3.82 & 3.62 & 11.8 & 11.2 & 0.57 \\
8-HQSABF - III & 47.6 & 47.2 & 3.85 & 3.65 & 10.1 & 9.97 & 0.57 \\
8-HQSABF - IV & 48 & 47.62 & 3.81 & 3.61 & 9.11 & 9.97 & 0.58 \\
\hline
\end{tabular}

\section{Electronic spectra}

The UV-Visible spectra (Figure 2) of all 8-HQSABF copolymers samples in pure $N$, $N$-dimethyl formamide were recorded in the region $190 \mathrm{~nm} 700 \mathrm{~nm}$. All the four 8-HQSABF copolymers samples displayed two characteristic broad bands at $290 \mathrm{~nm}$ and $335 \mathrm{~nm}$. These observed position for absorption bands indicate the presence of a carbonyl $(>\mathrm{C}=\mathrm{O}$ ) group having a carbon oxygen double bond which is in conjugation with the aromatic nucleus. The later band can be accounted for a $\pi \rightarrow \pi^{*}$ transition while the former band (less intense) may be due to a $\pi \rightarrow \pi^{*}$ transitions

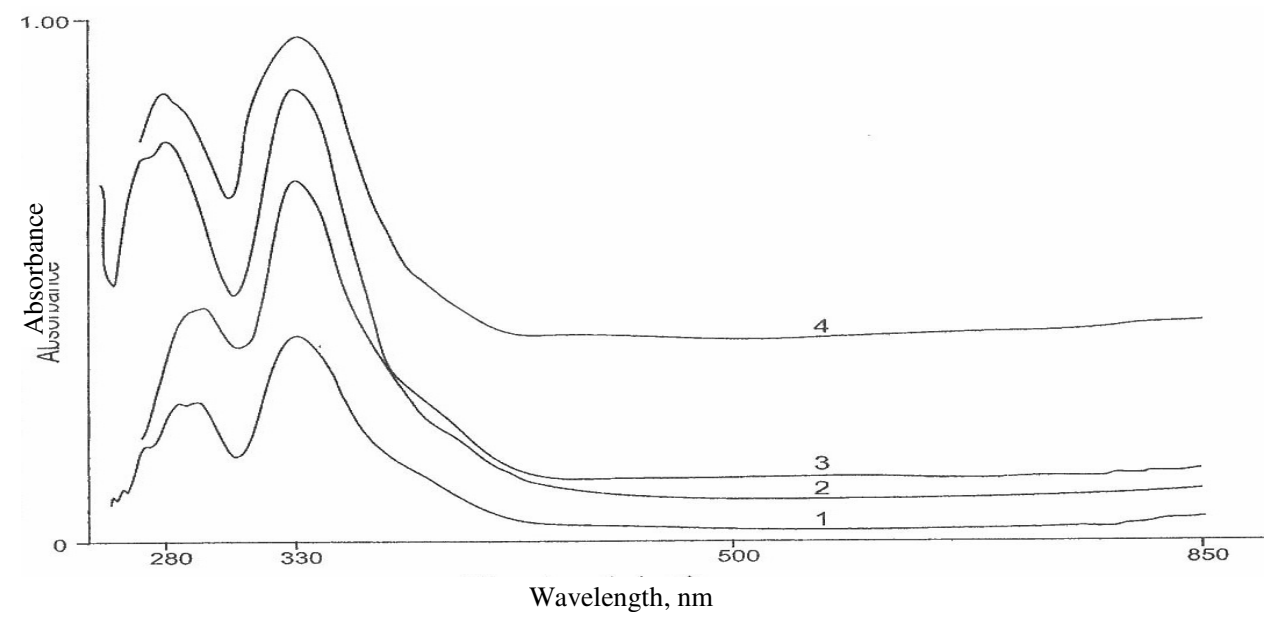

Figure 2. UV-Visible spectra of 8-HQSABF copolymer resins (1) 8-HQSABF-I (2) 8-HQSABF-II (3) 8-HQSABF-III (4) 8-HQSABF-IV

The bath chromic shift (shift towards longer wavelength) from the basic value of the $\mathrm{C}=\mathrm{O}$ group viz. $237 \mathrm{~nm}$, may be due to the combine effect of conjugation and phenolic hydroxyl group (auxochrome) ${ }^{12.13}$. It may be observed from the electronic spectra of the 8-HQSABF copolymers that the absorption intensity gradually increases in the order 8-HQSABF-I $<$ 8-HQSABF-II $<8$-HQSABF-III < 8-HQSABF-IV. The observed increasing order may be due to introduction of more chromophores $(\mathrm{C}=\mathrm{O}$ group) and auxochromes (phenolic $\mathrm{OH}$ ) in the repeat unit structure of the copolymers. 


\section{Infrared spectra}

The IR spectra of all four 8-HQSABF copolymers are presented in Figure 3. The IR spectra revealed that all these copolymers give rise to nearly similar pattern of spectra (Table 3). A band appeared in the region $3460 \mathrm{~cm}^{-1}$ may be assigned to the stretching vibration of the phenolic hydroxy group exhibiting intermolecular hydrogen bonding ${ }^{12}$. The presence of weak peak at $3140 \mathrm{~cm}^{-1}$ describes the $-\mathrm{NH}$ - The weak band at $3140 \mathrm{~cm}^{-1}$ indicates $-\mathrm{NH}$ group. The strong band of stretching vibrations of carbonyl group $(>\mathrm{C}=\mathrm{O})$ of both acid and oxamide molecules in resins ${ }^{13-15}$ is observed at $166 \mathrm{~cm}^{-1}$. The bands obtained at 800,1270 and $1350 \mathrm{~cm}^{-1}$ suggests the presence of methylene bridges in the polymer chain ${ }^{16}$. The sharp peaks at $1600 \mathrm{~cm}^{-1}$ and $1450 \mathrm{~cm}^{-1}$ indicate aromatic skeletal ring breathing modes ${ }^{17,18}$. The absorption bands at 980,1080 and 1135 recognize $1,4,5$ - trisubstituted phenyl ring ${ }^{19-20}$. The band at $1344 \mathrm{~cm}^{-1}$ indicates the presence of $\mathrm{SO}_{3} \mathrm{H}$ group.
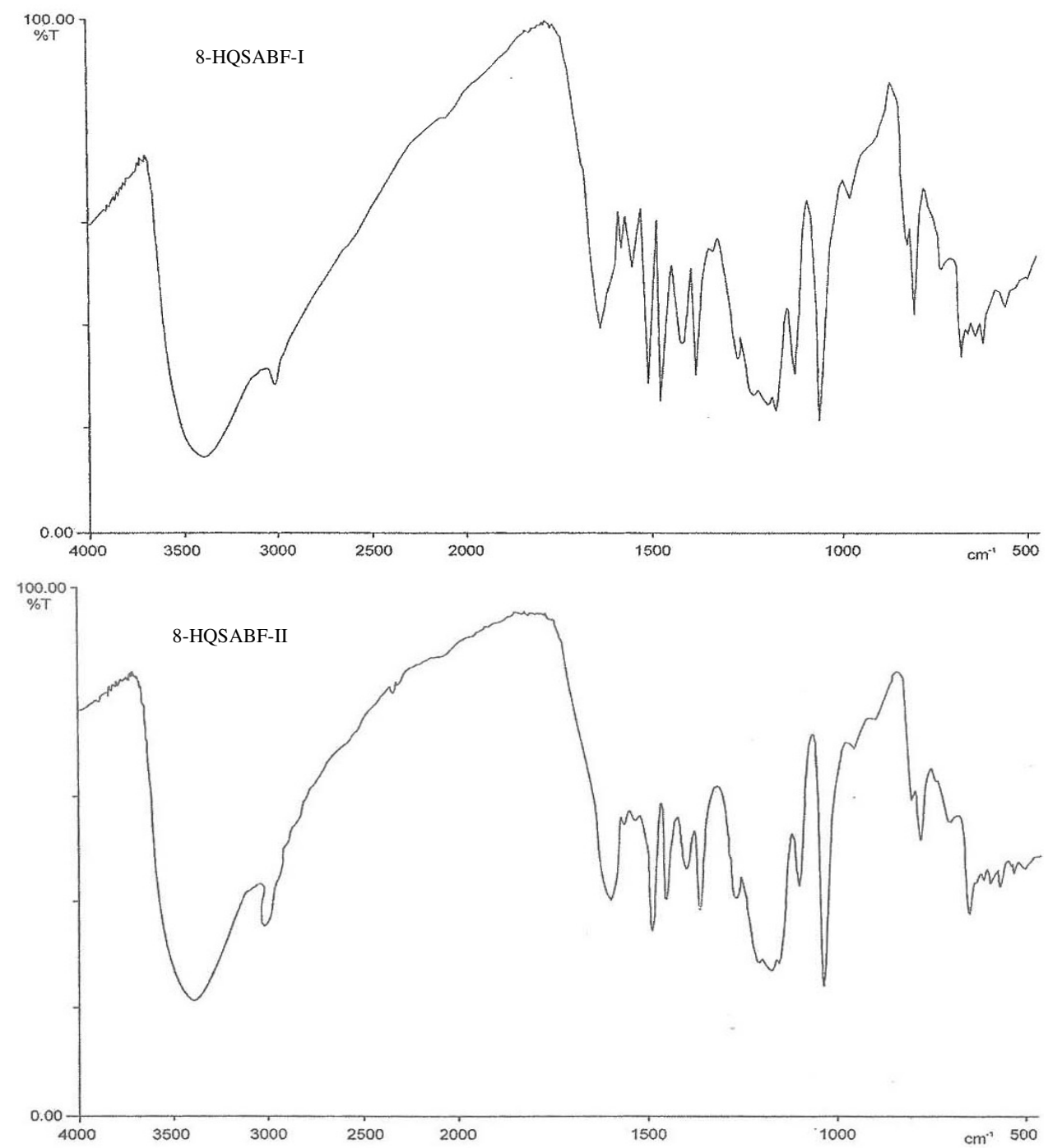

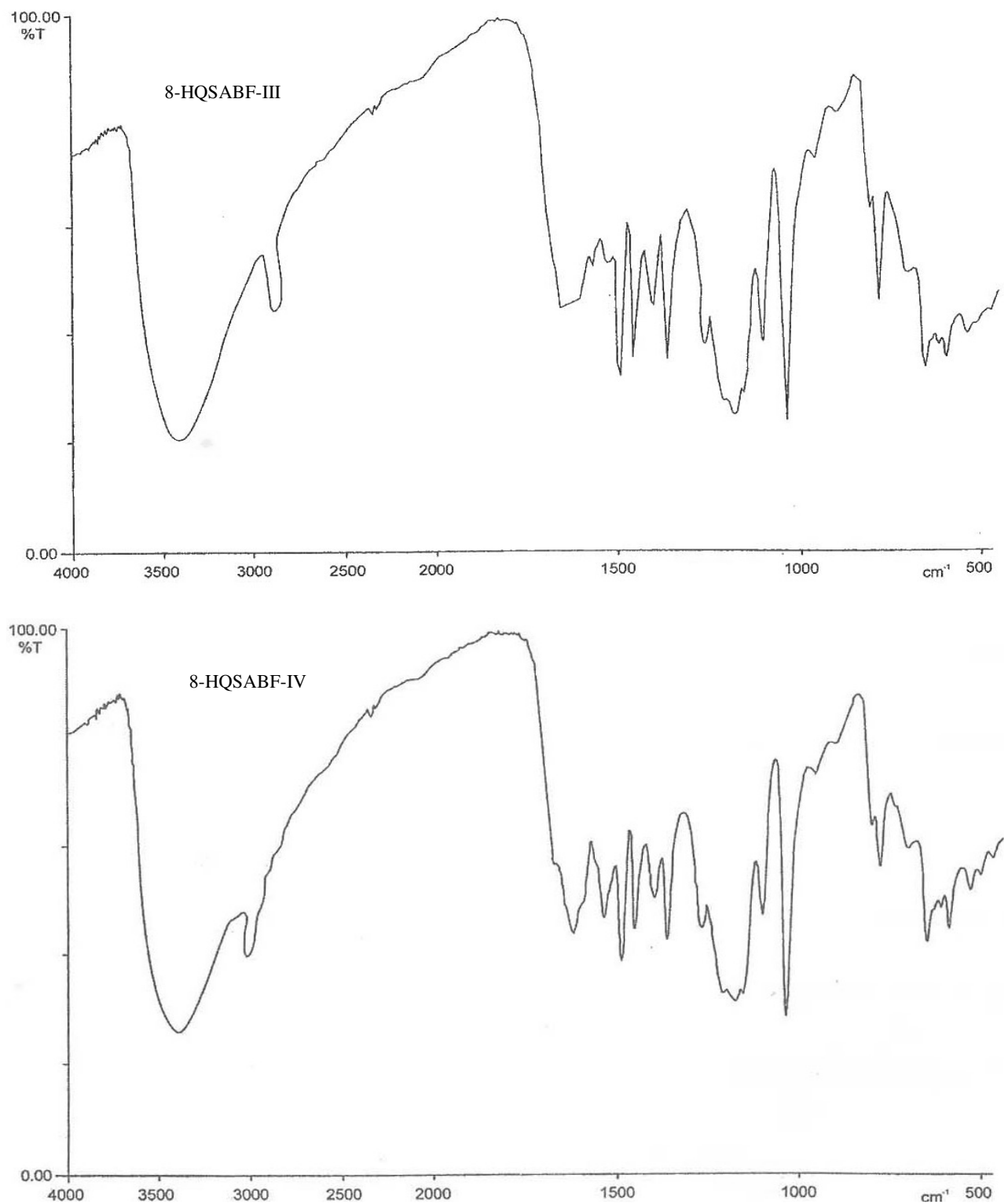

Figure 3. Infrared spectrum of copolymer resins 8-HQSABF-I, 8-HQSABF-II, 8-HQSABF-III, 8-HQSABF-IV

\section{$H$ - Nuclear magnetic resonance spectra}

${ }^{1} \mathrm{H}$ NMR spectra of all the four 8-HQSABF copolymers were scanned in dimethyl sulfoxide $-\mathrm{d}_{6}$. The spectral data are given in Table 4 and the spectra are presented in Figure 4. From the spectra it is revealed that all the 8-HQSABF copolymers gave rise to different pattern of ${ }^{1} \mathrm{H}$ NMR spectra, since each of the 8-HQSABF copolymers posses set of proton different electronic environments. 
Table 3. Infrared spectral data of 8- HQSABF copolymer resins

\begin{tabular}{|c|c|c|c|c|}
\hline \multicolumn{4}{|c|}{ Observed band frequency, $\mathrm{cm}^{-1}$} & \multirow{3}{*}{ Assignment } \\
\hline \multicolumn{4}{|c|}{ Copolymer resins } & \\
\hline 8-HQSABF-I & 8-HQSABF-II & 8-HQSABF-III & 8-HQSABF-IV & \\
\hline 3460 & 3450 & 3460 & 3450 & -OH stretching \\
\hline (b) & (b) & (b) & (b) & (Phenolic) \\
\hline 3140 & 3154 & 3160 & 3140 & $>\mathrm{NH}$ Stretching \\
\hline (b) & (b) & (b) & (b) & (Imido) \\
\hline 1630 & 1640 & 1635 & 1630 & \\
\hline (st) & (st) & (st) & $(\mathrm{st})$ & $>\mathrm{C}=\mathrm{O}$ group \\
\hline (W) & $1340(w)$ & $1340(w)$ & $1340(w)$ & \\
\hline $1270(\mathrm{st})$ & $1270(\mathrm{st})$ & $1270(\mathrm{st})$ & $1270(\mathrm{st})$ & $>\mathrm{CH}_{2}$ \\
\hline 790 (st) & $790(\mathrm{~s})$ & $800(\mathrm{~s})$ & $790(\mathrm{~s})$ & \\
\hline $1600(\mathrm{st})$ & $1600(\mathrm{st})$ & $1600(\mathrm{st})$ & $1600(\mathrm{st})$ & \\
\hline $1450(\mathrm{st})$ & $1450(\mathrm{st})$ & $1450(\mathrm{st})$ & $1450(\mathrm{st})$ & Aromatic ring \\
\hline $1080(\mathrm{st})$ & $1080($ st) & $1080(\mathrm{st})$ & $1080(\mathrm{st})$ & Substitution \\
\hline $1195(\mathrm{st})$ & $1200(s)$ & $1200(s)$ & $1200(s)$ & $\begin{array}{l}\text { Subsutution } \\
\text { In Renzene }\end{array}$ \\
\hline $1185(\mathrm{st})$ & $1190(s)$ & $1190(s)$ & $1190(s)$ & m benzene \\
\hline 1498 (st) & $1500(\mathrm{~s})$ & $1500(\mathrm{~s})$ & $1500(\mathrm{~s})$ & \\
\hline 1343 & 1344 & 1348 & 1344 & SO3H group \\
\hline
\end{tabular}

$B=$ broad, st $=$ strong, $s=$ sharp, $w=$ weak

Table 4. Nuclear magnetic resonance spectral data of 8-HQSABF copolymer resins

\begin{tabular}{|c|c|c|c|c|}
\hline \multicolumn{4}{|c|}{ Observed chemical shift $\delta, \mathrm{ppm}$} & \multirow{2}{*}{$\begin{array}{l}\text { Nature of protons } \\
\text { assigned }\end{array}$} \\
\hline 8-HQSABF-I & 8-HQSABF-II & 8-HQSABF-III & 8-HQSABF-IV & \\
\hline 8.5 & 8.8 & 8.8 & 8.5 & $\begin{array}{l}\text { Proton of phenolic- } \mathrm{OH} \\
\text { (intramolecular H-bond) }\end{array}$ \\
\hline 7.0 & 7.0 & 7.2 & 7.2 & $\begin{array}{c}\text { Aromatic Proton } \\
\text { (Unsymmetrical Pattern) }\end{array}$ \\
\hline $4.2-4.6$ & $4.2-4.5$ & $4.3-4.7$ & $4.6-4.9$ & Proton of - NH-bridges \\
\hline 4.0 & $4.1-4.4$ & $4.1-4.4$ & $4.1-4.4$ & $\begin{array}{l}\text { Methylenic proton of } \\
\mathrm{ArCH}_{2}-\mathrm{N} \text { moiety }\end{array}$ \\
\hline- & - & 3.8 & 3.8 & Proton of $\mathrm{Ar}-\mathrm{CH}_{2} \mathrm{Ar}$ \\
\hline 10.1 & 10.1 & 10.1 & 10.1 & Proton of $\mathrm{SO}_{3} \mathrm{H}$ \\
\hline
\end{tabular}

NMR spectra show the intense signal appeared in the region 8.5 to $8.8 \delta$ (ppm) which is characteristic of phenolic hydroxyl protons. This downfield chemical shift for protons of phenolic - $\mathrm{OH}$ clearly indicates the intermolecular hydrogen bonding of $-\mathrm{OH}$ with carbonyl group of Ar-COOH present at the adjacent ortho position ${ }^{13}$. A sharp intense signal at 7.0-7.2 $\delta(\mathrm{ppm})$ is assigned to aromatic proton ${ }^{13}$. A weak broad signal in the region 4.3 to $4.9 \delta$ (ppm) may be due to protons of -NH-bridges ${ }^{21,22}$. The methylenic protons of $\mathrm{Ar}_{-} \mathrm{CH}_{2}-\mathrm{N}$ moiety may be recognized from signals which appeared in the range 4.0 to $4.4 \delta(\mathrm{ppm})^{2}$.

Except 8-HQSABF-I, 8-HQSABF-II, copolymer, the remaining two copolymers 8-HQSABF-III, 8-HQSABF-IV show signals around $3.9 \delta(\mathrm{ppm})$ suggesting the presence of a methylene bridges of $\mathrm{Ar}-\mathrm{CH}_{2}-\mathrm{Ar}$ linkage ${ }^{13}$. The signal appear at $10^{-1}$ indicates the proton of $\mathrm{SO}_{3} \mathrm{H}$ group. 

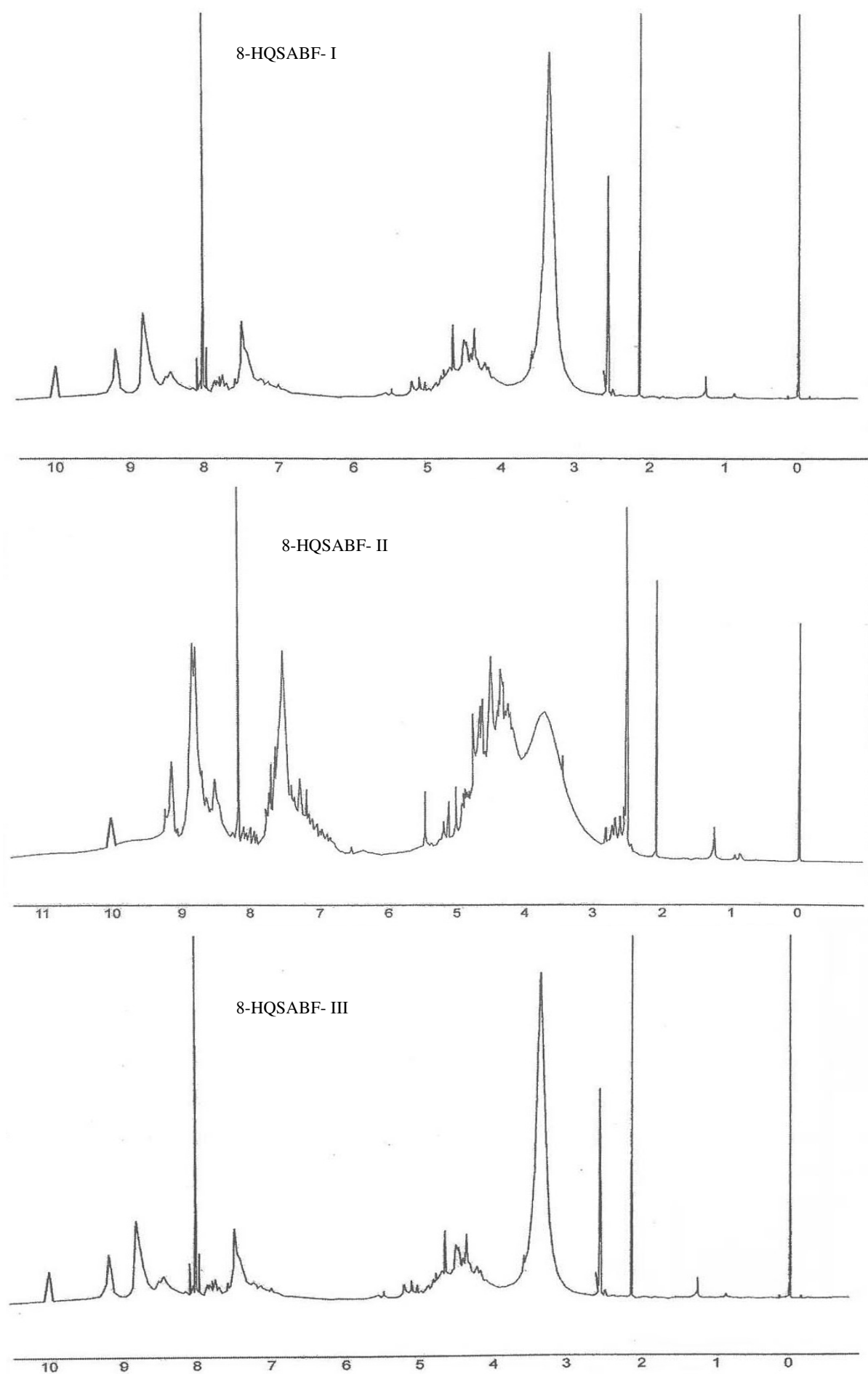


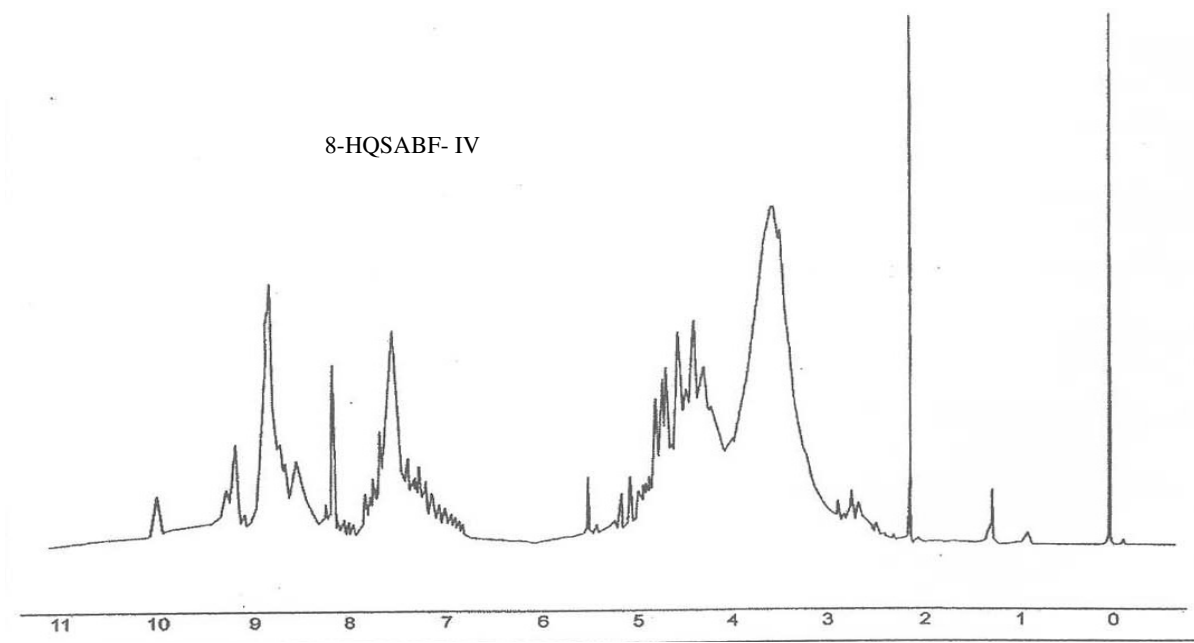

Figure 4. Proton NMR spectrum of copolymer resins 8-HQSABF-I, 8-HQSABF-II, 8-HQSABF- III, 8-HQSABF- IV

On the basis of the nature and reactive position of the monomer elemental analysis, electronic, IR, NMR spectra and molecular weight, the most probable structures have been proposed for these copolymers as shown in Figure 5.

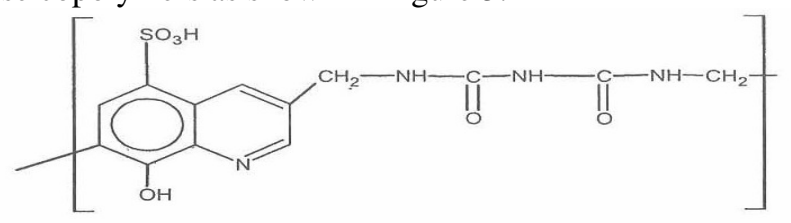

8-HQSABF-I

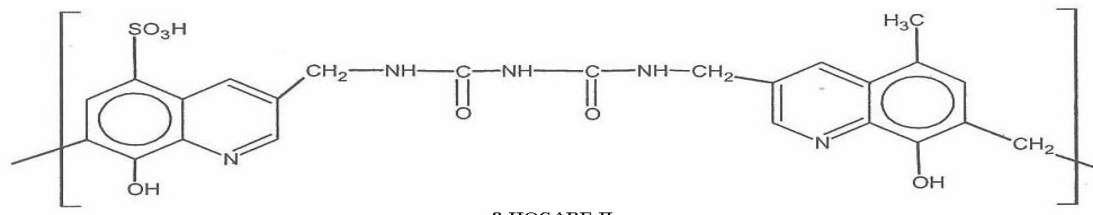

8 HOSAPF<smiles>CCCCCc1cc(O)c2cc(CNC(=O)NCCNC(=O)CNCc3cnc4c(O)c(-c5nc6c(O)c(C)cc(O)c6cc5C)cc(O)c4c3)cnc2c1O</smiles>

8-HQSABF-III

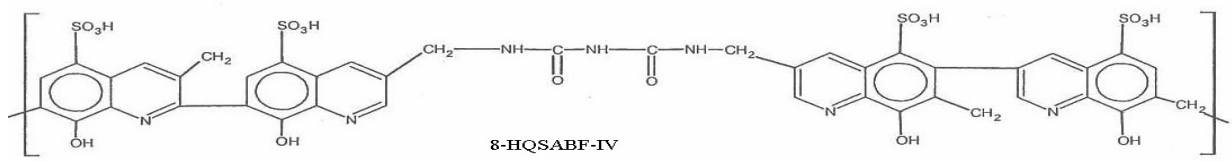

Figure 5. Structure of 8-HQSABF-I, 8-HQSABF-II, 8-HQSABF-III, 8-HQSABF-IV 


\section{Ion exchange properties}

The results of the batch equilibrium study carried out with the copolymers sample 8-HQSABF-I, 8-HQSABF-II, 8-HQSABF-III, 8-HQSABF-IV are presented in Tables 5-7. Form the study with four metal ions under limited variation of experimental conditions, certain generalization may be made about the behavior of the copolymers sample.

\section{Effect of electrolytes on metal uptakes}

The data presented in Table 5 reveal that the amount of metal ions taken up for a given amount of resin sample depends on the nature and concentration of electrolyte present in the solution. In presence of per chlorate, chloride and nitrate ions, the amount of $\mathrm{Cu}(\mathrm{II})$, ion taken up by the copolymer samples increases while in presence of sulphate ions the amount of above mentioned ions taken up by the resin samples decreases with increasing concentration of electrolyte ${ }^{24}$. Moreover, the amount of $\mathrm{Co}(\mathrm{II}), \mathrm{Zn}(\mathrm{II})$ and $\mathrm{Cd}(\mathrm{II})$ ions taken up by the copolymer samples decreases with increasing concentration of per chlorate, chloride, nitrate and sulphate ions. This may be explained on the basis of stability constants of the complexes with $\mathrm{Cu}$ (II), $\mathrm{Co}(\mathrm{II}), \mathrm{Zn}(\mathrm{II})$ and $\mathrm{Cd}(\mathrm{II})$ metal cations ${ }^{24,25}$.

Table 5. Evaluation of influence of different electrolytes on the uptake of metal

\begin{tabular}{ccccc}
\hline \multirow{2}{*}{ Metal ion } & \multirow{2}{*}{ Concentration } & $\mathrm{NaClO}_{4}$ & $\mathrm{NaCl}$ & $\mathrm{NaNO}_{2}$ \\
\cline { 2 - 5 } $\mathrm{Cu}(\mathrm{II})$ & 0.01 & 0.09 & 0.10 & 0.33 \\
& 0.05 & 0.27 & 0.27 & 0.33 \\
& 0.1 & 0.43 & 0.45 & 0.27 \\
& 0.5 & 0.57 & 0.60 & 0.15 \\
$\mathrm{Cd}$ (II) & 1 & 0.65 & 0.68 & 0.08 \\
& 0.01 & 0.17 & 0.25 & 0.35 \\
& 0.05 & 0.49 & 0.50 & 0.27 \\
& 0.1 & 0.65 & 0.74 & 0.21 \\
$\mathrm{Cos}$ (II) & 0.5 & 0.86 & 0.90 & 0.15 \\
& 1 & 0.99 & 1.07 & 0.07 \\
& 0.01 & 0.39 & 0.086 & 0.16 \\
& 0.05 & 0.14 & 0.21 & 0.12 \\
$\mathrm{Zn}$ (II) & 0.1 & 0.29 & 0.34 & 0.10 \\
& 0.5 & 0.40 & 0.42 & 0.08 \\
& 1 & 0.50 & 0.50 & 0.27 \\
& 0.01 & 0.19 & 0.17 & 0.17 \\
& 0.05 & 0.34 & 0.27 & 0.10 \\
& 0.1 & 0.43 & 0.37 & 0.06 \\
& 0.5 & 0.50 & 0.50 & 0.05 \\
& 1 & 0.59 & 0.64 & 0.02 \\
\hline
\end{tabular}

Volume of metal ion solution $=2.0 \mathrm{~mL}$ of $0.1 \mathrm{M}$ metal nitrate, Volume of electrolyte solution $=25 \mathrm{~mL}$ of $1 \mathrm{M} \mathrm{NaNO}$, Time $=24$ h (Equilibrium state),Temperature $=300 \mathrm{~K}$

This observed order may be due to introduction of more and more ligand groups in the repeating unit of the copolymer resins. It has also been noticed that a lower $\mathrm{pH}$ was not suitable when concentrated electrolytes were used. This effect was much more pronounced in copolymers containing higher content of salicylic acid. Therefore, it can be concluded that the copolymers of low molar ratio, to a certain extent improves the stability of the copolymer when used as an ion-exchanger, without affection much the metal uptake. It was also observed that generally the metal ion adsorption by the copolymer samples in much better in presence of $1 \mathrm{M}$ per chlorate solution. 


\section{Evaluation of the rate of metal uptake}

The rates of metal adsorption by the 8-HQSABF copolymers were measured for $\mathrm{Cu}(\mathrm{II}), \mathrm{Zn}(\mathrm{II})$, $\mathrm{Cd}(\mathrm{II})$ and $\mathrm{Co}(\mathrm{II})$ ions, in order to know the time required to reach the equilibrium. The tern "rate" refers merely to the change in the concentration of the metal ions in the aqueous solution which is in contact with the given copolymer resins. The experimental results which are given in Table 6 show that the time taken for the uptake of the different metal ions at a given stage depends on the nature of the metal ion under given conditions. Examination of results indicates that $\mathrm{Cu}(\mathrm{II})$ ions require time of $5 \mathrm{~h}$ for the establishment of the equilibrium. $\mathrm{Co}(\mathrm{II}), \mathrm{Zn}(\mathrm{II})$ and $\mathrm{Cd}(\mathrm{II})$ ions require about $6 \mathrm{~h}$ for the establishment of the equilibrium.

Table 6. Comparison of the rates of metal ion uptake by 8-HQSABF-I resin

\begin{tabular}{cccccccc}
\hline Metal & \multirow{2}{*}{\begin{tabular}{c}
\multirow{2}{*}{ ion } \\
Copolymer
\end{tabular}} & \multicolumn{6}{c}{ Percentage of the amount of metal ion taken up at different time, $\mathrm{h}$} \\
\cline { 2 - 8 } & & 1 & 2 & 3 & 4 & 5 & 6 \\
\hline $\mathrm{Cu}(\mathrm{II})$ & 8-HQSABF-I & 12 & 24 & 44 & 55.5 & 71.6 & 75 \\
$\mathrm{Co}(\mathrm{II})$ & 8-HQSABF-I & 7.5 & 34 & 51 & 63.5 & 69.5 & 77 \\
$\mathrm{Zn}(\mathrm{II})$ & 8-HQSABF-I & 7.5 & 24 & 39.5 & 50.5 & 56.5 & 72 \\
$\mathrm{Cd}(\mathrm{II})$ & 8-HQSABF-I & 7.5 & 27 & 43.5 & 57 & 70.5 & 77 \\
\hline
\end{tabular}

Volume of metal ion solution=2.0 $\mathrm{mL}$ of $0.1 \mathrm{M}$ metal nitrate, Volume of electrolyte solution $=25 \mathrm{~mL}$ of $1 \mathrm{MNaNO}_{3}$, Time $=24 \mathrm{~h}$. (Equilibrium state), Temperature $=300 \mathrm{~K}$

\section{Evaluation of distribution of metal ion over wide $\mathrm{pH}$ range}

The results of the effect of $\mathrm{pH}$ on the amount of metal ion distributed between two phases are incorporated in Table 7 examination of the data indicates that the relative amount of metal ions taken up by the resin samples at equilibrium increases with increasing $\mathrm{pH}$. The study was carried out only up down $\mathrm{pH}=6.5$ in order to prevent hydrolysis of the metal ions at higher $\mathrm{pH}$.

Table 7. Distribution ratio $\mathrm{D}^{*}$ of different metal ions as function of $\mathrm{pH}$ by 8-HQSABF-I resin

\begin{tabular}{|c|c|c|c|c|c|c|c|c|}
\hline \multirow[t]{2}{*}{ Metal ion } & \multirow[t]{2}{*}{ Copolymer } & \multicolumn{7}{|c|}{$\begin{array}{l}\text { Percentage of the amount of metal ion taken up at different } \\
\text { time (hours) }\end{array}$} \\
\hline & & 2.5 & 3.0 & 3.5 & 4.0 & 5.0 & 6.0 & 6.5 \\
\hline $\mathrm{Cu}(\mathrm{II})$ & 8-HQSABF-I & 9.3 & 12.12 & 26.55 & 52.20 & 90.68 & 151.35 & 207.4 \\
\hline $\mathrm{Co}(\mathrm{II})$ & 8-HQSABF-I & 16.30 & 28.84 & 47.86 & 74.20 & 117.8 & 168.7 & 240.3 \\
\hline $\mathrm{Zn}(\mathrm{II})$ & 8-HQSABF-I & 6.69 & 34.5 & 69.84 & 104.34 & 197.84 & 202.5 & 252.9 \\
\hline $\mathrm{Cd}(\mathrm{II})$ & 8-HQSABF-I & 3.17 & 5.17 & 39.00 & 69.84 & 122.75 & 228.57 & 334.39 \\
\hline
\end{tabular}

Volume of metal ion solution=2.0 $\mathrm{mL}$ of $0.1 \mathrm{M}$ metal nitrate, Volume of electrolyte solution $=25 \mathrm{~mL}$ of $1 \mathrm{M} \mathrm{NaNO}$, Time $=24$ h. (Equilibrium state),Temperature $=300 \mathrm{~K}$

Among the other metal ions $\mathrm{Cu}(\mathrm{II})$ ions are taken up more selectively by copolymer resins. The other three metal ions $\mathrm{Co}(\mathrm{II}), \mathrm{Zn}(\mathrm{II})$ and $\mathrm{Cd}(\mathrm{II})$ ions, have a low distribution ratio ' $\mathrm{D}$ ' over the $\mathrm{pH}$ range 4 to 6.5 this could be attributed to the low stability constants ${ }^{26}$. Comparison of the value of distribution coefficients of a given metal ion for all the molar ratio of copolymer reveals that there is no much difference in the values. Thus in the present study the observed order of distribution ratio of metal ions measured in the range of 1.5 to $6.5 \mathrm{pH}$ was found to be

$$
\mathrm{Cu} \text { (II) }>\mathrm{Co} \text { II) }>\mathrm{Zn} \text { (II) }>\mathrm{Cd} \text { (II) }
$$

This order of selectivity has also been suggested for a salicylic acid containing polymer by earlier workers ${ }^{27}$. Thus, the results of this study are helpful in selecting the optimum $\mathrm{pH}$ for a selective uptake of a particular metal ion from a mixture of different metal ion. For example the results suggest the optimum $\mathrm{pH} 2.5$ for the separation of $\mathrm{Cu}(\mathrm{II})$. 


\section{Conclusion}

A copolymer 8-HQSABF base on the condensation reaction of 8-hydroxyquinoline-5sulphonic acid, biuret and formaldehyde in presence of acid catalyst has been prepared. It is a selective chelating ion exchange copolymer for cationic metal.The copolymer shows higher selective $\mathrm{Cu}^{2+}$ ions than for $\mathrm{Cd}^{2+}, \mathrm{Co}^{2+}, \mathrm{Zn}^{2+}$ ions.

\section{References}

1. Helfferich F, Ion Exchange Resins, Mc-Grow Hill: New York, 1962.

2. Kunin R, Ion Exchange Resins, $3^{\text {rd }}$ Ed., Wiley: New York, 1958.

3. Lutfor M Rand Silong S, Eur Polym J., 2000, 36, 2105.

4. $\quad$ Patel S A, Shah B S and Patel R M, Iran Polym J., 2004,13(6), 445-453.

5. Ibraheem K A K, Al-duhan J A and Himdi S T, Eur Polym J., 1985, 21, 97.

6. $\quad$ Dass S C, J Indian Chem Soc., 2000, 77, 69.

7. Rivas B L, Villegas S J and Munoz C, J App Polym Sci., 2004, 19(6), 3679-3685.

8. Jadhao M M, Paliwal L J and Bhave N S, J Appl Polym Sci., 2008, 109(1), 508-514.

9. Patel J R, Sutariya D H and Patel M N, React Polym., 1995, 25, 17.

10. Lingala P S, Paliwal L J and Juneja H D, Proc Nat Acad Sci., 2001, 7l(A), 205.

11. Michael P E P, Lingala P S, Juneja H D and Paliwal L J, J Appl Polym Sci., 2004, 92(4), 2278-2283.

12. Silverstein R M, Bassler G C and Morrill T C, Spectrometric Identification of Organic Compounds. $2^{\text {nd }}$ Ed., John Wiley, New York, 1987.

13. Silverstein R M and Bassler G C, Spectrometric Identification of Organic compounds ( $2^{\text {nd }}$ Ed.,) John Willey and Son, Inc, New York, 1967.

14. Dunn G E and Mc Donald R C, Can J Chem., 1969, 47, 4577.

15. Banwell C N, Fundamentals of Molecular Spectroscopy Tata Mc Graw Hill Pub. Co. Ltd. New Delhi, 1972.

16. Nakanishi K, Infrared Absorption Spectroscopy Practical. Holden Day Inc. and Nankodo Co. Ltd.. Tokyo, 1967.

17. Vogel A I, Textbook of Practical Organic Chemistry $5^{\text {th }}$ Ed., Longman Group Ltd., England, 1989.

18. Bellamy L J, The Infrared Spectra of Complex Molecules Methuen \& Co. Ltd. London John Wiley and Sons Inc New York, 1956, 1958.

19. $\quad$ Pal T K and Kharat R B, Indian J Chem., 1989, 28A, 55-58.

20. Patel M M and Manavalan R, Indian J Chem., 1983, 22A 390-394.

21. Dyer J R, Application of Absorption Spectroscopy of Organic Compounds, Prentice Hall of India, $2^{\text {nd }}$ Indian Reprint, New Delhi, 1971, 33.

22. Kalsi P S, Spectroscopy of Organic Compounds, Willey Eastern Limited, New Delhi.

23. Patel M M and Manavalan R, J Indian Chem Soc., 1984, 61(6), 490.

24 Pal T K and Kharat R B, J Indian Chem Soc., 1989, 66, 286.

25 Cotton F A and Wilkineon G, Advanced Inorganic Chemistry, $3^{\text {rd }}$ Edn., Interscience New York, 1972, 594.

26 Davadov S L and N A, Plate Coord Chem Rev., 1975, 16, 195.

27 Vermon F and Eccles H, Anal Chem Acta, 1974, 72, 331. 


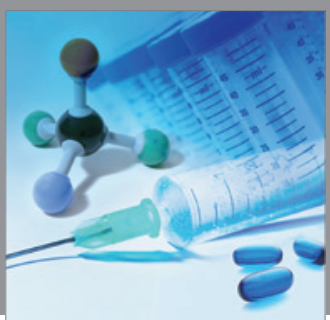

International Journal of

Medicinal Chemistry

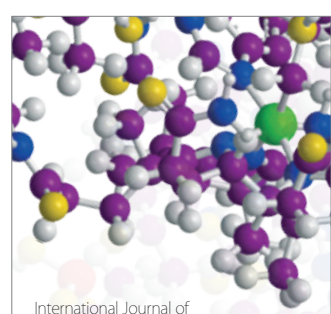

Carbohydrate Chemistry

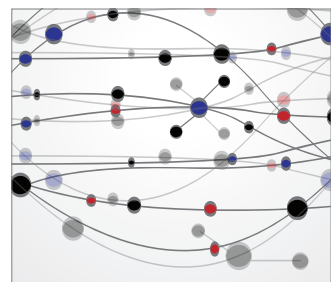

The Scientific World Journal
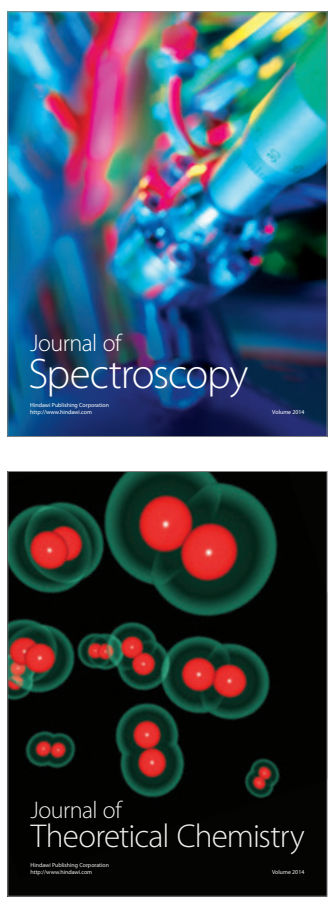
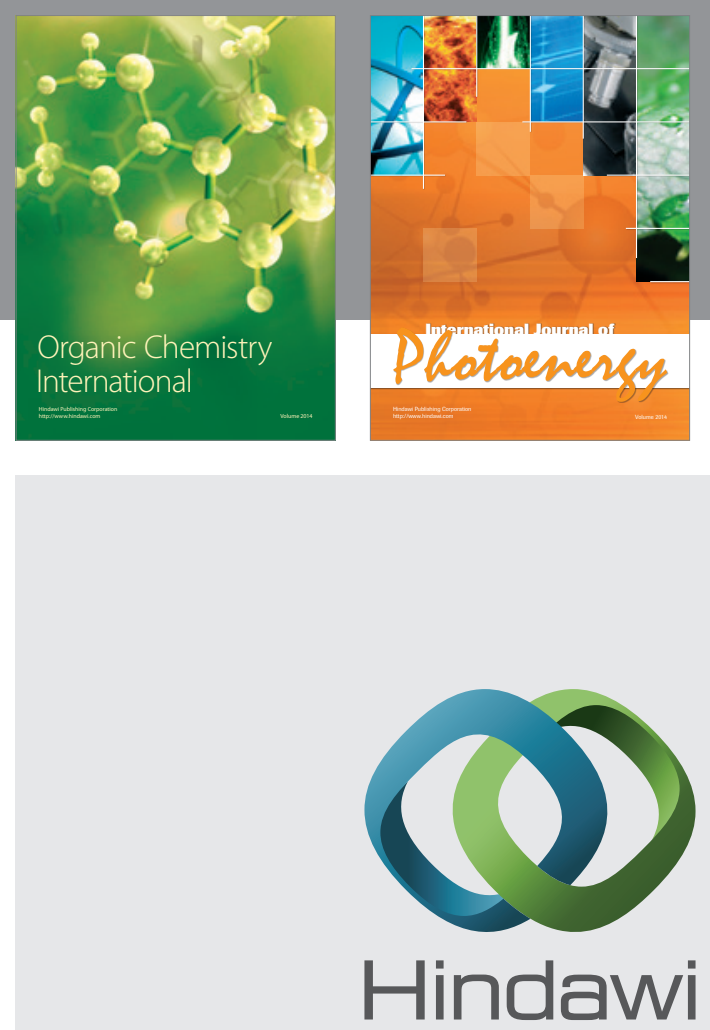

Submit your manuscripts at

http://www.hindawi.com
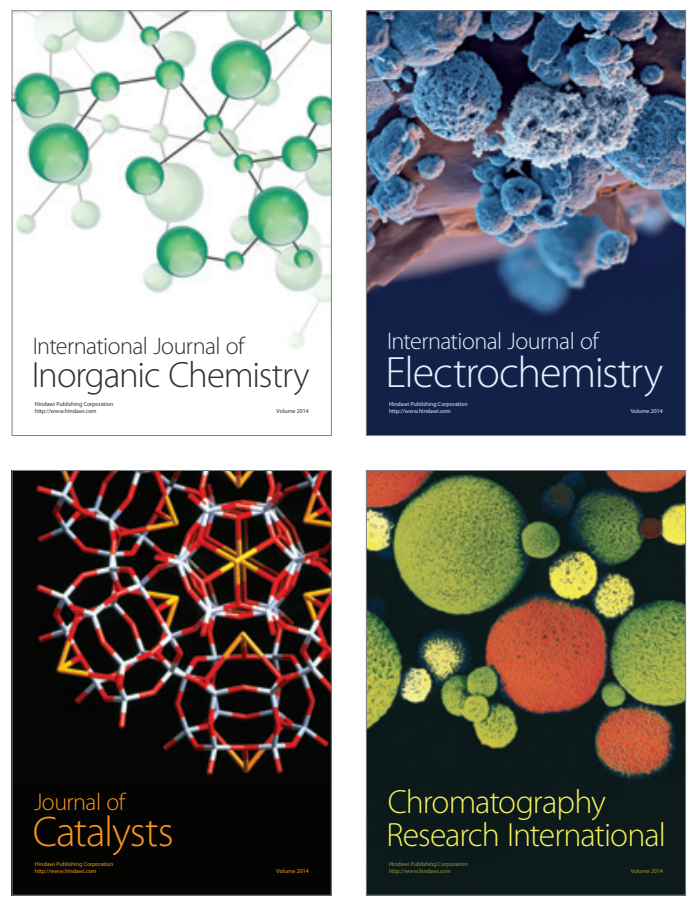
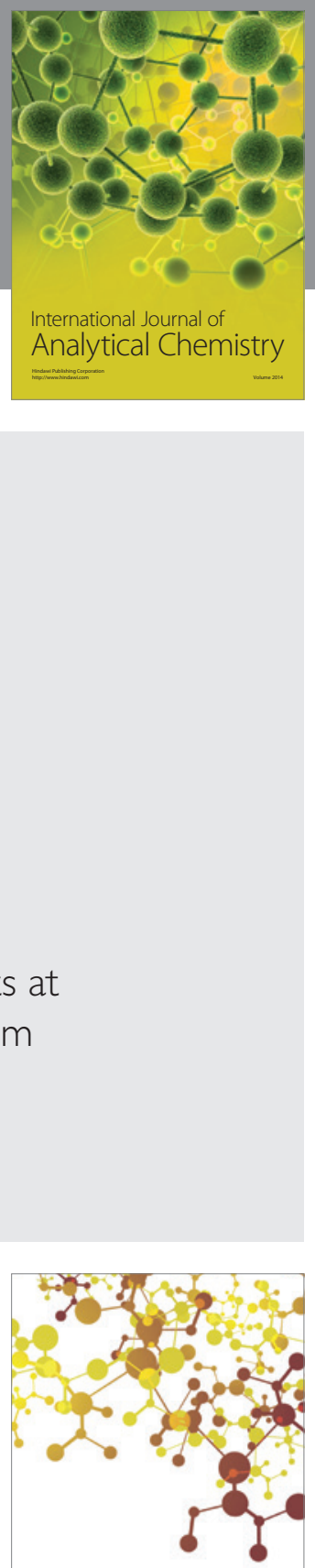

Journal of

Applied Chemistry
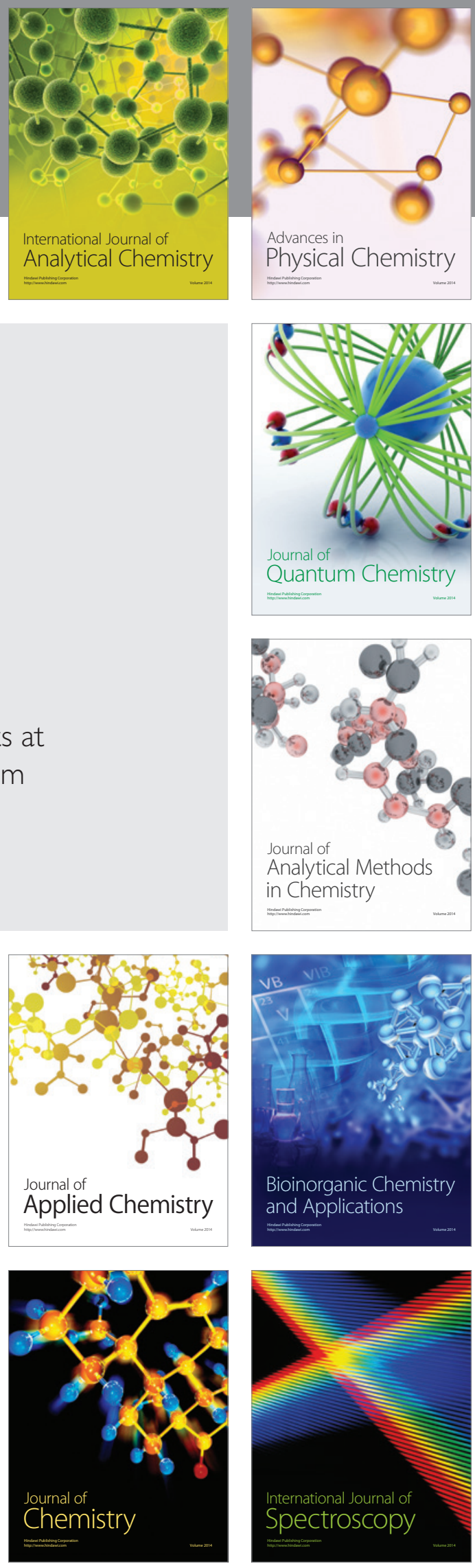